\title{
Longitudinal Evoked Potential Studies in Hereditary Ataxias
}

\author{
M.J. Taylor, W.Y. Chan-Lui*, W.J. Logan
}

\begin{abstract}
We studied multimodal evoked potentials (EPs) longitudinally in a series of children with Friedreich's ataxia and ataxia telangiectasia to determine both their diagnostic utility and their correlation with clinical regression.

The auditory brainstem responses (ABRs) were abnormal only in the children with Friedreich's ataxia. The abnormality seen in these patients was a rostral-caudal loss of the ABR waves. The visual EPs (VEPs) were abnormal in many of the patients; those with ataxia telangiectasia had unusually low amplitude or absent VEPs, occasionally with increased latencies, whereas those with Friedreich's ataxia had normal amplitude VEPs, often at increased latencies. The somatosensory EPs were usually of increased latency or absent in these patients. Unlike the ABR and VEPs, they did not serve to differentiate the groups.

Changes in the EPs appeared to reflect clinical deterioration; patients with little change in their EPs over several years were regressing very slowly, whereas others had rapid deterioration in both EPs and clinical status. We suggest that the EPs are diagnostically of value in degenerative ataxias and may be of value in monitoring these patients and their response to therapy.
\end{abstract}

RESUMÉ: Études des potentiels evoques à long terme dans les ataxies hereditaires Nous avons étudié longitudinalement les potentiels évoqués (EPs) multimodaux chez une série d'enfants avec ataxie de Friedreich et ataxie télangiectasie, afin de déterminer l'utilité diagnostique de ces tests et leur corrélation avec l'évolution clinique.

Les potentiels évoqués auditifs du tronc cérébral (ABRs) n'étaient anormaux que chez les enfants souffrant d'ataxie de Friedreich. Chez ces patients l'anomalie observée était une perte rostrocaudale des ondes ABR. Les potentiels évoqués visuels (VEPs) étaient anormaux chez plusieurs de ces patients; ceux qui souffraient d'ataxie télangiectasie présentaient une amplitude nettement basse ou même une absence de VEPs, parfois accompagnée de latences augmentées. Les Friedreich, par contre, avaient une amplitude normale des VEPs, souvent avec latence augmentée. Chez ces patients les potentiels somatosensitifs présentaient généralement une latence accrue ou absente. Par contre ces derniers potentiels, contrairement aux ABR et VEP ne pouvaient différencier les groupes.

Il semble que les changements observés des potentiels évoqués (EP) reflètent la détérioration de l'état clinique. Ceux qui n'avaient que peu de changements dans leurs EP sur une période de plusieurs années progressaient effectivement lentement en observation clinique. L'évolution clinique rapid se reflète également dans l'EP. Nous suggérons que les évoqués peuvent être utiles dans le diagnostic différentiel de certaines formes d'ataxie dégénératives et également dans l'évolution du taux de progression et de la réponse au traitement.

Can. J. Neurol. Sci. 1985; 12:100-105

The heterogeneity of hereditary, degenerative ataxias presents one of the most challenging diagnostic problems in paediatric neurology. In the early stages of these diseases when ataxia is the predominant feature, unaccompanied by other differentiating neurological or systemic abnormalities, an exact diagnostic classification is difficult. Prolonged follow-up, repeated investigations or postmortem examinations are often necessary before the diagnosis can be established.

Sensory evoked potentials can detect neurological dysfunction in the absence of clinically obvious neurological abnormality in inherited ataxias (e.g., Carroll et al., 1980; Pedersen \& Trojaborg, 1981; Nuwer et al., 1983). Despite the variability in the presentation and progression of these disorders, as reflected in the variability in electrophysiological abnormalities, there do appear to be characteristic differences among of the degenerative ataxias with such measures.

This study had two aims. The first was to evaluate the usefulness of multimodal sensory evoked potentials for differentiating between two of the more common degenerative ataxias in children, ataxia telangiectasia and Friedreich's ataxia. These two disorders, defined according to recognized criteria, served as model groups for this comparison. The second aim was to determine, through longitudinal assessments, whether the evoked potentials changed systematically with age and/or with alterations in the clinical state of these children.

\footnotetext{
From the Division of Neurology, Departments of Paediatrics and Medicine, The Hospital for Sick Children, University of Toronto, Toronto, Canada

*Present Address: Department of Paediatrics, Queen Mary Hospital, University of Hong Kong, Hong Kong

Received May 24, 1984. Accepted in revised form January 8, 1985.

Reprint requests to Dr. M.J. Taylor, Division of Neurology, Hospital for Sick Children, 555 University Avenue, Toronto, Ontario, Canada M5G 1 X8
} 


\section{MeThoDS}

Patients. We studied 14 patients with Friedreich's ataxia (7-21 years), all of whom satisfied the diagnostic criteria of the Quebec cooperative study (Geoffroy et al., 1976). The age of onset in these patients ranged from 3 to 11.5 years. The duration of the disease at the time of the most recent investigations ranged from 2 to 15.5 years. All had ataxia, areflexia and posterior column signs in the lower limbs. All but case 2 had scoliosis and 11 of 14 had pes cavus.

There were 13 patients with ataxia telangiectasia (6-26 years). The age of onset of clinical symptoms ranged from 1 to 5.5 years and the disease duration at time of testing was from 4 to 21.5 years. All the patients were ataxic, had telangiectasia, ocular apraxia, dysarthria, increased chromosomal breakage and increased alpha fetoproteins. All but case 7 had B and/or T cell deficiency; all but the two youngest were areflexic in the lower limbs (Boder \& Sedgwick, 1957, 1958; Baloh et al., 1978; Young et al., 1964; Jason \& Gelfand, 1979). The initial baseline studies in the ten older patients have been reported (Taylor \& Logan, 1983).

Procedure. Visual evoked potentials (VEPs) were recorded in response to reversing checkerboard pattern stimulation presented via a television display. The display subtended 12 degrees and the checks 30 minutes of arc and reversed at a rate of $2.0 / \mathrm{s}$. The bandpass was $1-100 \mathrm{~Hz}$, with a gain of $20 \mathrm{k}$ and a sweep of 200 or $250 \mathrm{~ms}$. VEPs were recorded over 01 and 02 referred to linked ears. Target fixation was monitored in all patients by observing the scleral reflection of the display. In the few patients in whom reproducible pattern VEPs could not be obtained, flash VEPs were recorded. The recording parameters were the same, except that electroretinograms (ERGs) were recorded simultaneously with the flash VEPs. A Grass PS22 photic stimulator, flash intensity at 8 , was used. All VEP testing was conducted in a darkened room. Sixty-four trials per average were recorded in response to monocular stimulation and at least two averages were collected per eye to assess replicability. The latencies of the N70 and P100 and the interpeak amplitude were measured.

Auditory brainstem responses (ABRs) were recorded between $\mathrm{Cz}$ and ipsilateral ear in response to $100 \mu \mathrm{s}$ rarefaction monaural click stimuli. The clicks were presented at $11 / \mathrm{s}$, at $70 \mathrm{dBHL}$; if clear responses were not obtained the stimuli were increased to 80 and, rarely, to $90 \mathrm{dBHL}$. Contralateral white noise masking (30 $\mathrm{dB}$ below click intensity) was used. The band-pass was $150-3000 \mathrm{~Hz}$ with a gain of $100 \mathrm{k}$ and a sweep of $10 \mathrm{~ms}$. Two averages of 1024 trials were obtained at each intensity level tested for each ear. The latencies of waves I through $V$, when identifiable, were measured.

Somatosensory evoked potentials (SEPs) were recorded over the cervical spine (C7) and contralateral sensory cortex (C3' and $\mathrm{C4}^{\prime}$ ) referenced to $\mathrm{Fpz}$. The eliciting stimuli were $.2 \mathrm{~ms}$ electrical pulses presented at $4.1 /$ s over the median nerve at the wrist. Stimulation intensity was gradually increased until a slight thumb movement was observed, and the studies were then run at that level of stimulation. This was determined for each arm. The bandpass for the SEPs was $30-3000 \mathrm{~Hz}$, the gain was $40 \mathrm{k}$ and the sweep time was $50 \mathrm{~ms}$. The latencies of the cervical N12 and N13 and the cortical P15, N18 and P22 components were measured. For all the studies Grass gold cup electrodes were used; the impedance was always below $5 \mathrm{k}$ ohms.

Normative values for the ABRs were obtained from a group of 24 children $4-18$ years ( 12 females), for the VEPs from a group of 20 children 4-16 years, and for the SEPs from a group of 45 children (3-17 years). Adult norms were established for each of the modalities with a group of 20 young adults. The normative values were age corrected for the VEPs and size and age corrected for the SEPs. The upper limits of normal in all latency and amplitude measures across modalities were +2.5 standard deviations.

\begin{tabular}{|c|c|c|c|c|c|c|}
\hline Case & Age & $\begin{array}{c}\text { Duration } \\
\text { (yrs.) }\end{array}$ & $\begin{array}{c}\text { ABRs } \\
\text { R/L } \\
\text { (waves present) }\end{array}$ & $\begin{array}{l}\text { VEPs } \\
\text { R/L }\end{array}$ & $\begin{array}{c}\text { cortical } \\
\text { SEPs } \\
\text { R/L }\end{array}$ & $\begin{array}{c}\text { spinal } \\
\text { SEPs } \\
\text { R/L }\end{array}$ \\
\hline 1 & 7 & 2 & I/I-II & $\uparrow / \uparrow$ & $a b / \uparrow$ & $\uparrow / 4$ \\
\hline 2 & 7 & 3 & I-V/I-V & $4 / N$ & $\uparrow / \uparrow$ & $\uparrow / \uparrow$ \\
\hline 3 & 14.5 & 3 & I-V/I-III & $4 / 4$ & $\uparrow / \uparrow$ & $N / 4$ \\
\hline 4 & 20 & 4 & I-IV/I-IV & $\mathbf{N} / \mathbf{N}$ & + ah & N/ab \\
\hline 5 & 15 & 4.5 & 1/ab & $a b / a b$ & $N / \uparrow$ & $a b / a b$ \\
\hline 6 & 7 & 6 & I-IV/I-IV & $\uparrow / \uparrow$ & $a b /-$ & $a b /-$ \\
\hline 7 & 9 & 6 & I-IV?V/I-III & $N / N$ & $a b / a b$ & $a b / a b$ \\
\hline 8 & 15 & 7 & I-IV/I-IV & $4 / 4$ & $\uparrow / a b$ & $\uparrow / \uparrow$ \\
\hline 9 & 19 & 7 & I-IV/I-IV?V & $\mathrm{N} / \mathrm{N}$ & $a b / t$ & $a b / a b$ \\
\hline 10 & 17 & 7 & I-II/I-II & $4 / 4$ & $a b / a b$ & $a b / a b$ \\
\hline 11 & 13.5 & 8.5 & $\mathrm{ab} / \mathrm{ab}$ & $N / N$ & $-/ a b$ & $-/ a b$ \\
\hline 12 & 18 & 13 & I/I & $\uparrow / \uparrow$ & $a b / a b$ & $\mathrm{ab} / \mathrm{ab}$ \\
\hline 13 & 21 & 15 & $\mathrm{ab} / ? \mathrm{I}$ & $4 / 4$ & $a b / a b$ & $a b / a b$ \\
\hline 14 & 20.5 & 15.5 & $a b / a b$ & $\uparrow / \uparrow$ & $a b / a b$ & $+/ a b$ \\
\hline
\end{tabular}

$\mathrm{N}$ normal

+ increased latency

ab absent

- not tested

? questionable component 
Table 2: EP findings in patients with Ataxia Telangiectasia

\begin{tabular}{|c|c|c|c|c|c|c|}
\hline Case & Age & $\begin{array}{c}\text { Duration } \\
\text { (yrs.) }\end{array}$ & $\begin{array}{c}\mathbf{A B R s} \\
\mathbf{R} / \mathbf{L}\end{array}$ & $\begin{array}{l}\text { VEPs } \\
\text { R/L }\end{array}$ & $\begin{array}{c}\text { cortical } \\
\text { SEPs } \\
\text { R/L }\end{array}$ & $\begin{array}{c}\text { spinal } \\
\text { SEPs } \\
\text { R/L }\end{array}$ \\
\hline 1 & 6 & 4 & $\mathrm{~N} / \mathrm{N}$ & $a b / N$ & $4 / N$ & $4 / N$ \\
\hline 3 & 9 & 6 & $\mathrm{~N} / \mathrm{N}$ & $\mathrm{N} / \mathrm{N}$ & $\mathrm{N} / \mathrm{N}$ & $\mathrm{N} / \mathrm{N}$ \\
\hline 4 & 10 & 8 & $\mathrm{~N} / \mathrm{N}$ & $\begin{array}{l}a b / a b \\
4(f)\end{array}$ & $4 / a b$ & $a b / a b$ \\
\hline 7 & 12 & 10.5 & $\mathrm{~N} / \mathrm{N}$ & $\mathrm{N} / \mathrm{t}$ & $1 / 4$ & $4+14 t$ \\
\hline 8 & 12 & 11 & $\mathbf{N} / \mathbf{N}$ & $\begin{array}{c}a b / a b \\
N / N(f)\end{array}$ & $4 / 4$ & $a b / 4$ \\
\hline 9 & 15.5 & 14 & N/N & $\%$ & $\%$ & $\%$ \\
\hline 10 & 17 & 15.5 & $\mathrm{~N} / \uparrow$ & $\begin{array}{c}a b / a b \\
\downarrow / \downarrow(f)\end{array}$ & $a b / 4$ & $a b / a b$ \\
\hline 11 & 17.5 & 16.5 & $\mathrm{~N} / \mathrm{N}$ & $1+14 t$ & $\mathrm{ab} / \mathrm{ab}$ & $\mathrm{ab} / \mathrm{ab}$ \\
\hline
\end{tabular}

- decreased amplitude

increased latency

ab absent

- not tested

(f) flash VEP

\section{Results}

Abnormal evoked potentials in at least one modality were found in all but one of the patients and there were marked differences in the pattern of abnormalities found in Friedreich's ataxia and ataxia telangiectasia. Tables 1 and 2 summarize the abnormalities found in the two groups at the most recent testing.

ABR abnormalities were found consistently only in the Friedreich's ataxia patients. There was a rostral-caudal loss of components of the ABR with increasing severity of the disorder. Figure 1 shows ABRs from five children with Friedreich's ataxia who have been symptomatic for the indicated number of years; Figure 2 shows serial recordings from one child over a period of rapid clinical deterioration. Of all the patients with ataxia that we have studied, only the Friedreich's ataxia and three possible Friedreich's ataxia patients showed this unusual abnormality. With the exception of one patient with an increased 1-11I interpeak latency, all of the ABRs recorded from the ataxia telangiectasia group were within normal limits. One of the remarkable observations in this group of patients was the normality of the ABRs in morphology and latency, in contrast to their poorly reproducible and abnormal VEPs and SEPs.

The VEPs were abnormal in 11 of 13 of the ataxia telangiectasia patients. The principal abnormality was a reduction of VEP amplitude over one or both occipital lobes with either left or right eye stimulation. Four also had increased latencies (Figure 3). The abnormalities increased with age, and were more marked in the recent testing sessions than in sessions over the previous few years. In four of the more severely affected patients pattern VEPs could not be detected although they had been elicited a year or more previously. The VEP amplitude may have decreased to a level indistinguishable from background noise. In these patients flash VEPs were recorded, but even these were of reduced amplitude in 3 of 5 (Figure 4). Both a and b waves of the flash ERGs obtained in the patients were of normal amplitude and latency.

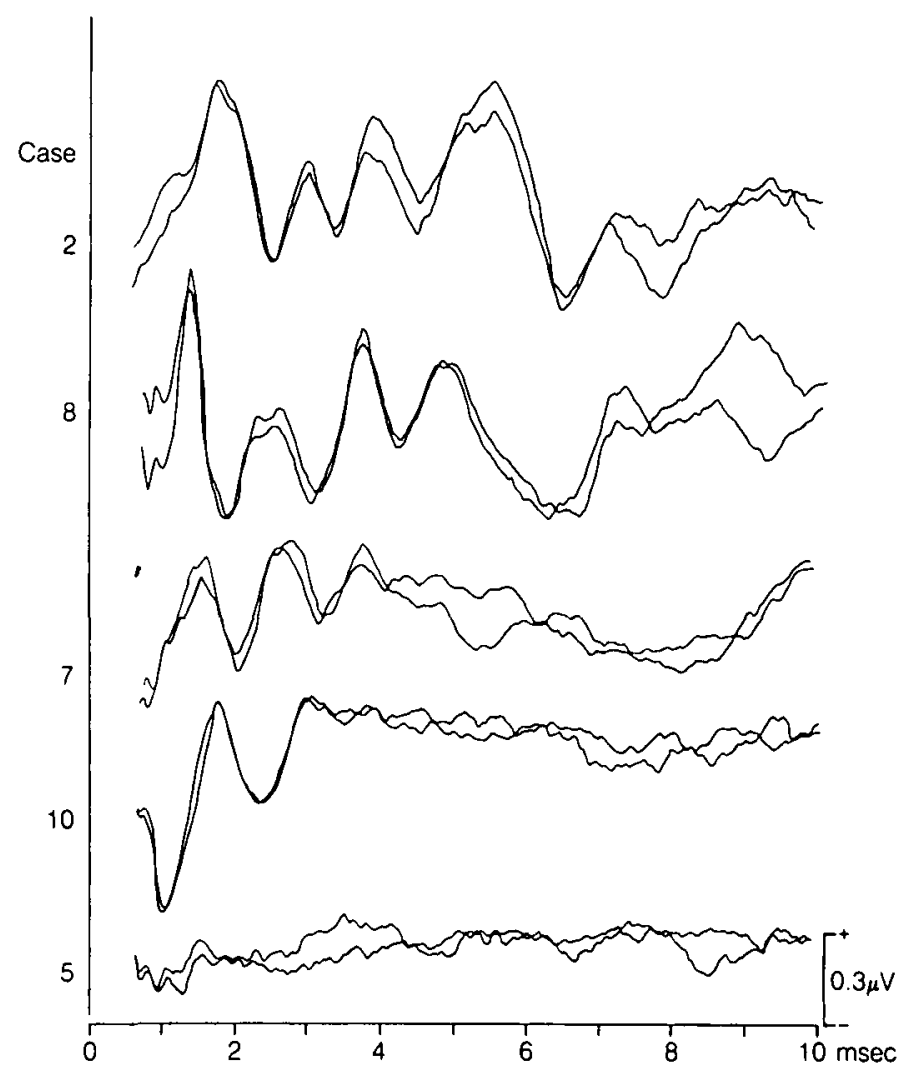

Figure I - ABRs from five patients with Friedreich's ataxia. Case 8 is very slowly progressing while case 5 has had a much more rapid deterioration. reflected in the comparative integrity of their ABRs. All these ABRs are from left ear stimulation at $80 \mathrm{dBHL}$ (more components are seen at 80 $d B H L$ than at $70 \mathrm{dBHL}$, but there is not usually much further improvement in wave clarity with $90 \mathrm{dBHL}$ ). 


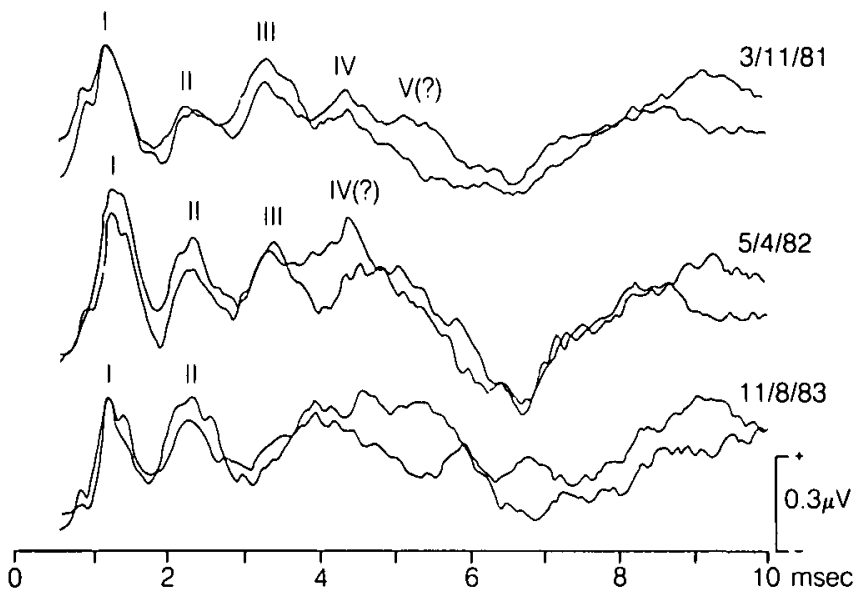

Figure $2-A B R$ s from the youngest patient with Friedreich's ataxia, who is showing very rapid progression of the disorder, demonstrating the rostralcaudal loss of the components over two years. This progressive loss of components was also seen in seven other Friedreich's ataxia patients.
$O_{1}$

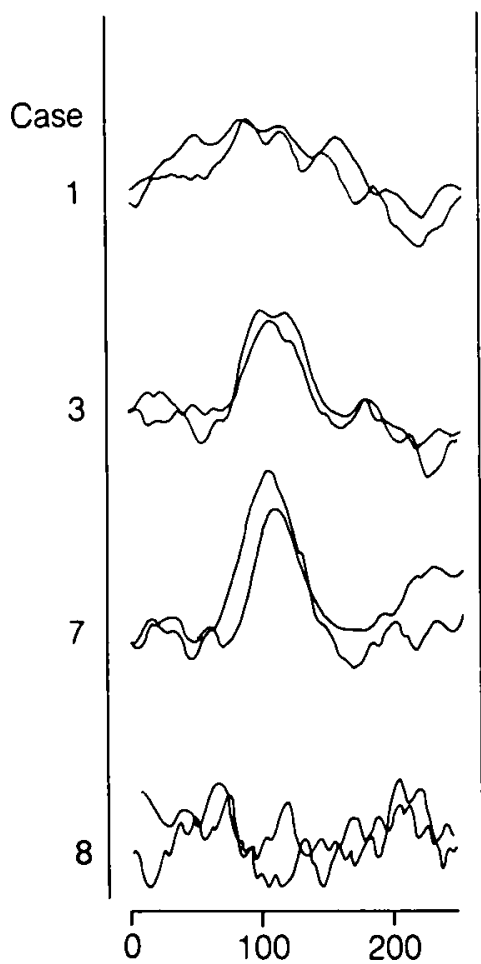

$\mathrm{O}_{2}$

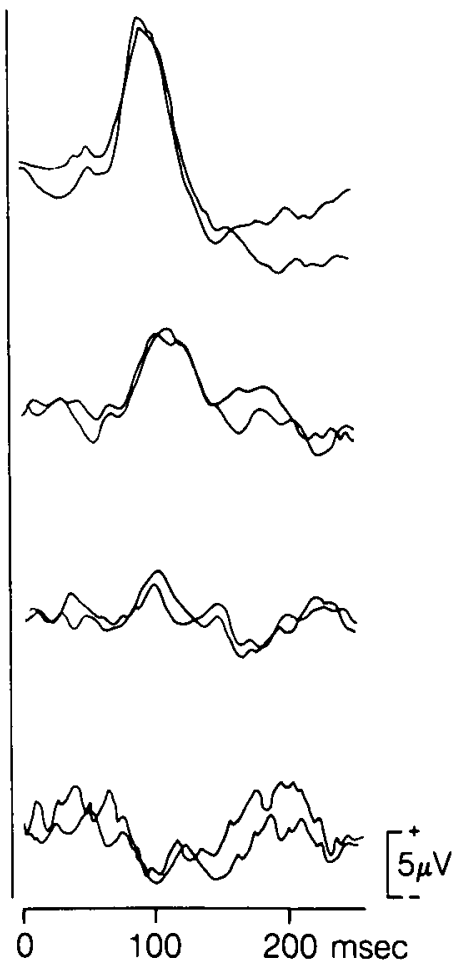

Figure 3 -VEPs from four patients with ataxia telangiectasia, showing the frequently asymmetrical, small amplitude responses, most often with normal latencies.

In the patients with Friedreich's ataxia the VEP data were more variable. They were abnormal in 10 of 14 cases, with an increase in the latencies of the major components. The latency increases tended to worsen with age (Figure 5), but did not parallel the abnormalities in the other sensory systems (Table 1). The VEPs were not significantly decreased in amplitude or absent in any of the Friedreich's ataxia patients.

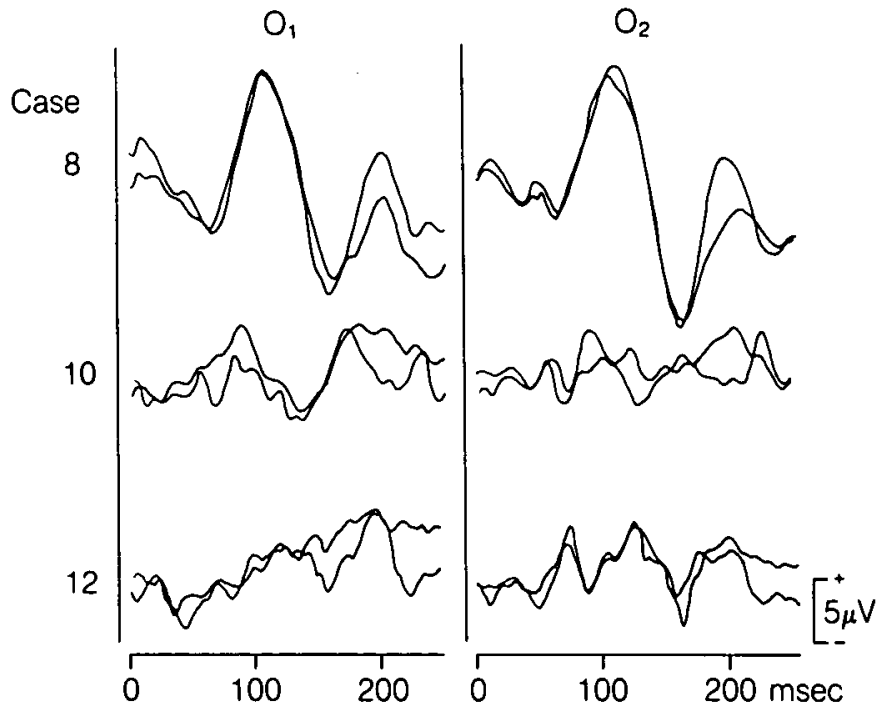

Figure 4 - Flash VEPs from 3 patients with ataxia telangiectasiafrom whom no recordable pattern VEPs could be obtained at the latest testing. The $V E P$ s in case 8 are within normal limits for flash stimulation, the other wo show poorly formed and low amplitude, questionable responses.

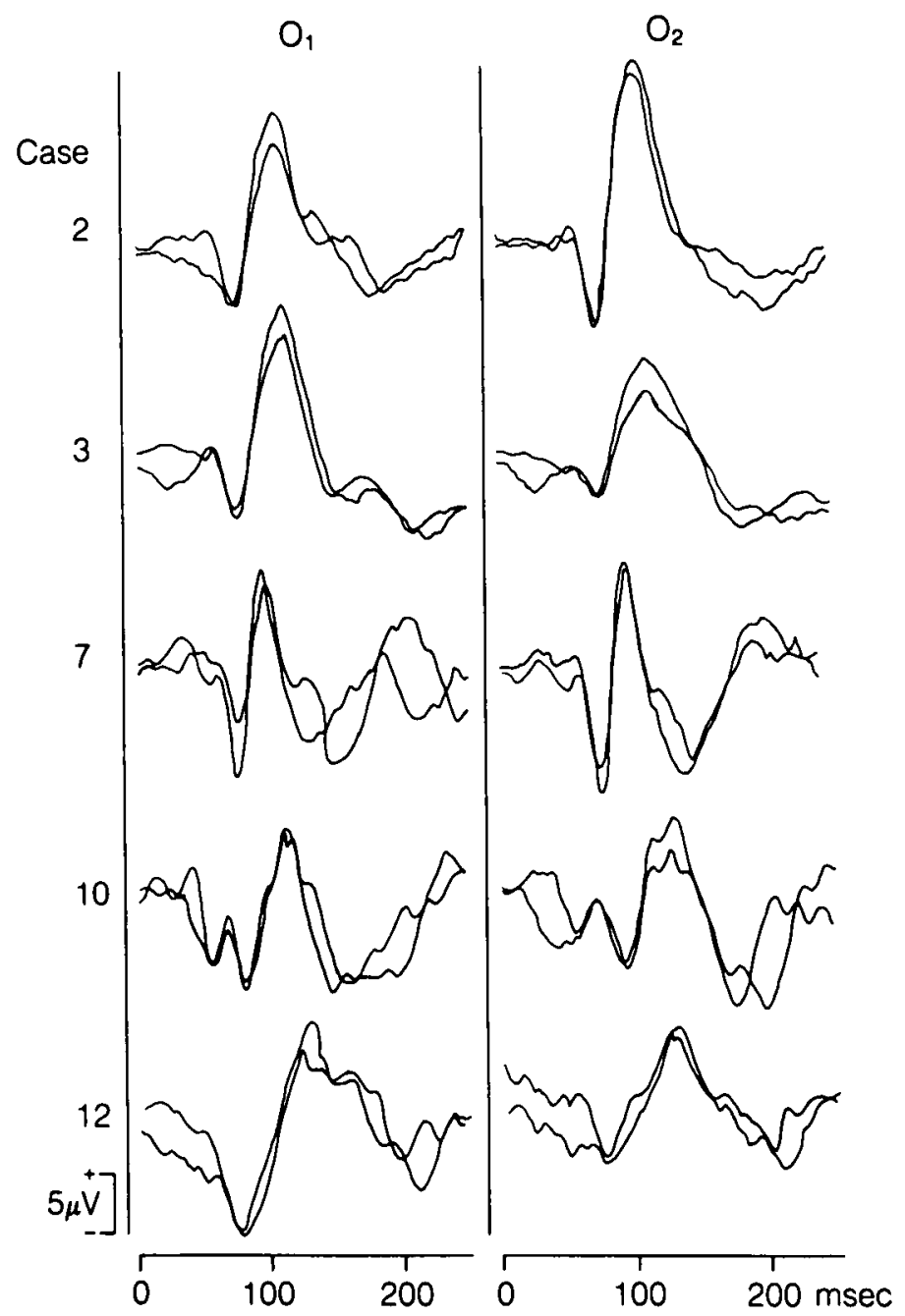

Figure 5-VEPs from five patients with Friedreich's ataxia. The latencies of case 7 are normal, those of case 2 at the upper limits of normal and the others beyond normal limits. All VEPs are in response to pattern reversal stimulation to the left eye. 
The SEPs were abnormal in almost all of the ataxia patients we studied. In only the younger patients could SEPs be recorded, and in all but two ataxia telangiectasia cases they were of increased latency compared to size and age matched controls. In the older patients of both groups reliable SEPs could not be obtained. No responses could be recorded bilaterally in 2 ataxia telangiectasia and 6 Friedreich's ataxia patients and unilaterally in 3 ataxia telangiectasia and 6 Friedreich's ataxia patients. Responses could be recorded at the cervical spine in 7 patients in whom the cortical waves were absent. Neither the cortical nor spinal SEPs appeared to change systematically over the few years that these patients have been followed, although they were more often abnormal in the older patients.

\section{Discussion}

This study demonstrates characteristic profiles for Friedreich's ataxia and ataxia telangiectasia patients with multimodal evoked potentials which, although they become more accentuated with age, are distinct even in quite young patients. An important aspect of this report is the documentation of the progressive changes in the EPs. The hypothesized changes in the ABRs and VEPS as a function of disease severity based on cross-sectional data (Taylor et al., 1982; Taylor \& Logan, 1983) has been supported with the present longitudinal data. The children with slow progression had only slight deterioration in their ABRs or VEPs over the period monitored; in those with a more rapid clinical course the EP changes were more dramatic.

At present we believe that the ABR abnormalities reported by Taylor et al. (1982) and replicated in the present series of Friedreich's ataxia patients are probably pathognomonic of this disorder, within the groups of hereditary degenerative ataxias. Clearly, this type of abnormality can be found in other neurological disorders (e.g., Starr \& Hamilton, 1976; Ochs et al., 1979; Chiappa et al., 1980) but the progressive deterioration has not to our knowledge been documented in any hereditary ataxia other than Friedreich's. The consistently small VEPs, in turn, appear to be a feature of ataxia telangiectasia. Although this may help differentiate between ataxia telangiectasia and other ataxias, caution needs to be exercised with this use of the VEPs, as intersubject amplitude variability is marked in normals and can be affected by recording parameters.

Unlike ABRs and VEPs, the SEPs did not co-vary with the type of degenerative ataxia and would not facilitate discrimination between Friedreich's ataxia and ataxia telangiectasia. This is not surprising considering the degenerative process in these disorders. Dorsal root ganglion degeneration occurs in both, accompanied by peripheral neuropathy involving loss of large myelinated fibres and the loss of axons and demyelination of the posterior columns (Dyck et al., 1971; Hughes et al., 1968; Martinez et al., 1977; Young et al., 1964). Axonal swelling and astrogliosis is found in the gracilis and cuneate nuclei and medial lemniscus, demyelination is also seen in the latter (Aguilar et al., 1968; Perry et al., 1984; Strich, 1966; Oppenheimer, 1979). This system degeneration occurs more slowly and is less severe, however, in ataxia telangiectasia (Aguilar et al., 1968; Dunn, 1973) as shown with both the relative preservation of the tactile senses and the more easily recorded SEPs in these patients. Other aspects of the sensory-motor systems are differentially affected in these diseases such as corticospinal and spinothalamic tract involvement in Friedreich's (Hughes et al., 1968) and cerebellar atrophy and anterior horn cell degeneration in ataxia telangiectasia (Aguilar et al., 1968; Strich, 1966; Perry et al., 1984), however, damage in these structures can not be seen with current evoked potential techniques. With these exceptions, the neuropathological and neurophysiological findings concur in these disorders. Both peripheral and central conduction abnormalities have been reported in Friedreich's ataxia (McLeod, 1971; Oh \& Halsey, 1973; Bouchard et al., 1979; Ouvrier et al., 1982; Jones et al., 1980; Noel \& Desmedt, 1980) and in ataxia telangiectasia (Dunn, 1973; Martinez et al., 1977; Taylor \& Logan, 1983). The frequency of SEP abnormalities in various ataxias, however, precludes their use as a specific diagnostic aid. Rather, their utility is in early detection and documentation of CNS disease.

The difference in the EP abnormalities in the two groups of ataxia patients in the other modalities, however, do reflect differences in underlying pathophysiology of the diseases. Neuropathological studies in Friedreich's ataxia have found cell loss and gliosis throughout the auditory brainstem pathway (Oppenheimer, 1979), but the rostral-caudal loss of ABR components suggests that the neuropathological changes first involve the midbrain then the pons and finally the VIIIth nerve. Despite the documentation of massive loss of inner hair cells in the cochlea in Friedreich's ataxia (Spoendlin, 1974), none of the present series of patients had clinically evident audiological abnormalities. In the majority of Friedreich's ataxia cases, the pathology in this system is demonstrated in electrophysiological but not audiological testing (see however, Shanon et al., 1981). In contrast to Friedreich's ataxia and consistent with their ABR results, the brainstem and subcortical structures are grossly and microscopically normal in ataxia telangiectasia (Strich, 1966; Solitaire \& Lopez, 1967).

The VEP abnormalities characteristic of ataxia telangiectasia are probably due to axonal loss in the visual pathways, leading to the reduced amplitudes; the delayed latencies found in a few patients could be due to secondary para-nodal demyelination. Supporting evidence comes from a recent neuropathological study on ataxia telangiectasia which found abnormalities throughout the visual system (Hinton \& Becker, 1984). The receptor layer of the retina was normal, but cell loss and reactive gliosis were found in the ganglion cells of the retina. This is consistent with the present findings of normal flash ERGs as these reflect the activity of retinal receptor layer only (Maffei \& Fiorentini, 1981; Kirkham \& Coupland, 1981). Mild gliosis in the optic radiation and significant neuronal degeneration in layer 5 of the occipital cortex were also reported (Hinton \& Becker, 1984). Both axonal loss and cortical atrophy in the occipital lobes may contribute to the small amplitude VEPs in these patients.

Although we find the EPs useful diagnostically, they may play a greater role clinically as therapy becomes available for the degenerative ataxias. As the EPs are sensitive measures of progression of subclinical damage in the sensory systems of these patients, they may be a valuable way of monitoring the efficacy of a particular therapeutic regime. The SEPs, as the most vulnerable of the EPs in these ataxia patients, may be more useful in the early stages of the diseases, whereas in older patients the ABRs and VEPs would probably be more useful in Friedreich's ataxia and ataxia telangiectasia, respectively. The results of this study indicate that EPs may serve as a prognostic measure; marked changes in the EPs parallel significant clinical 
deterioration, whereas only slight changes in the EPs over time correlate with subsequent slow clinical change.

\section{ACKNOWLEDGEMENTS}

We wish to thank Dr. L.E. Becker for his helpful comments on this manuscript, and Ms. J.M. Pearce for her excellent technical assistance. This research was supported in part by the Grotto Cerebral Palsy Foundation.

\section{REFERENCES}

Aguilar MJ, Kamoshita S, Landing BH et al. (1968) Pathological observations in ataxia-telangiectasia. J. Exp. Neurol. 27: 659-676.

Baloh RW, Yee RD, Boder E (1978) Eye movements in ataxia telangiectasia. Neurology 28: 1099-1104.

Boder E, Sedgwick RP (1957) A familial syndrome of progressive cerebellar ataxia oculocutaneous telangiectasia, and frequent pulmonary infection. A preliminary report on 7 children, and autopsy, and a case history. University of Southern California Medical Bulletin 9: 15-22.

Boder E, Sedgewick RP(1958) Ataxia telangiectasia, a familial syndrome of progressive cerebellar ataxia, oculocutaneous telangiectasia, and frequent pulmonary infection. Pediatrics 21: 526-554.

Bouchard JP, Barbeau A, Bouchard R, Bouchard RW (1979) Electromyography and nerve conduction studies in Friedreich's ataxia and autosomal recessive spastic ataxia of Charlevoix-Saguenay (ARSACS). Can. J. Neurol. Sci. 6: 185-189.

Carroll WM, Kriss A, Baraitser M, Barrett G, Halliday AM (1980) The incidence and nature of visual pathway involvement in Friedreich's ataxia. A clinical and visual evoked potential study of 22 patients. Brain 103: 413-434.

Chiappa KH, Harrison JL, Brooks EB, Young RR (1980) Brainstem auditory evoked responses in 200 patients with multiple sclerosis. Ann. Neurol. 7: 135-143.

Dunn HG (1973) Nerve conduction studies in children with Friedreich's ataxia and ataxia-telangiectasia. Devel. Med. Child Neurol. 15: 324-337.

Dunn HG, Meuwissen H, Livingstone CS, Pump KK (1964) Ataxia telangiectasia. Canad. Med. Assoc. J. 91: 1106-1118.

Dyck PJ, Lambert EH, Nichols PC (197!) Quantitative measurement of sensation related to compound action potential and number and sizes of myelinated and unmyelinated fibres of sural nerve in health, Friedreich's ataxia, hereditary sensory neuropathy, and tabes dorsalis. In: A. Remond (ed.), Handbook of electroencephalography and clinical neurophysiology, 9: 83-118.

Hinton DS, Becker LE (1984) Personal communication regarding data in preparation for publication.

Hughes JT, Brownell B, Hewer RL (1968) The peripheral sensory pathway in Friedreich's ataxia. Brain 91: 803-818.

Jones SJ, Baraitser M, Halliday AM (1980) Peripheral and central somatosensory nerve conduction defects in Friedreich's ataxia. J. Neurol. Neurosurg. Psychiat. 43: 495-503.
Jason JM, Gelfand EW (1979) Diagnostic consideration in ataxia telangiectasia. Arch. Dis. Child. 54: 682-686.

Kirkham TH, Coupland SG (1981) Abnormal pattern electroretingrams with macular cherry-red spots: evidence for selective ganglion cell damage. Current Eye Res. I: 367-372.

Maffei L, Fiorentini A (1981) Electroretinographic responses to alternate gratings before and after section of the optic nerve. Science 211: 953-955.

Martinez A-Cruz, Barrio M, Gutierrez AM, Lopez E (1977) Abnormalities in sensory and mixed evoked potentials in ataxia telangiectasia. $J$. Neurol. Neurosurg. Psychiat. 40: 44-49.

McLeod JG (1971) An electrophysiological and pathological study of peripheral nerves in Friedreich's ataxia. J. Neurol. Sci. 12: 333-349.

Noel P, Desmedt JE (1980) Cerebral and far-field somatosensory evoked potentials in neurological disorders involving the cervical spinal cord, brainstem, thalamus and cortex. Prog. Clin. Neurophysiol. 7: 205-230.

Nuwer MR, Perlman SL, Packwood JW, Kark RAP (1983) Evoked potential abnormalities in the various inherited ataxias. Ann. Neurol. 13: 20-27.

Ochs R, Markand ON, DeMeyer WE (1979) Brainstem auditory evoked responses in leukodystrophies. Neurology 29: 1089-1093.

Oh SJ. Halsey JH (Jr.) (1973) Abnormality in nerve potentials in Friedreich's ataxia. Neurology 23: 52-54.

Oppenheimer DR (1979) Brain lesions in Friedreich's ataxia. Can. J. Neurol. Sci. 6: 173-176.

Ouvrier RA, McLeod JG, Conchin TE (1982) Friedreich's ataxia. Early detection and progression of peripheral nerve abnormalities. J. Neurol. Sci. 55: 137-145.

Pedersen L. Trojaborg W (1981) Visual, auditory and somatosensory pathway involvement in hereditary cerebellar ataxia, Friedreich's ataxia and familial spastic paraplegia. Electroenceph. Clin. Neurophys. 52: 283-297.

Perry TL, Becker LE et al. (1984) Neuropathological and neurochemicalabnormalities in ataxia telangiectasia. Neurol 34: 187-191.

Shanon E, Himelfarb MZ, Gold S (1981) Auditory function in Friedreich's ataxia. Electrophysiologic study of a family. Arch. Otolaryngol. 107: 254-256.

Solitaire GB, Lopez VF (1967) Louis-Bar's syndrome (ataxia telangiectasia). Neuropathologic observations. Neurology 17: 23-31.

Spoendlin $H$ (1974) Optic and cochleovestibular degenerations in hereditary ataxias. Brain 97: 41-48.

Starr A, Hamilton AE (1976) Correlation between confirmed sites of neurological lesions and abnormalities of far-field auditory brainstem Electroenceph Clin. Neurophys. 41: 595-608.

Strich SJ (1966) Pathological findings in three cases of ataxia-telangiectasia. J. Neurol. Neurosurg. Psychiat. 29: 489-499.

Taylor MJ, Logan WJ (1983) Multimodal electrophysiological assessment of ataxia telangiectasia. Can. J. Neurol. Sci. 10: 261-265.

Taylor MJ, McMenamin JB, Andermann E, Watters GV (1982) Electrophysiological investigation of the auditory system in Friedreich's ataxia. Can. J. Neurol. Sci. 9: 131-135.

Young RR, Austen KF, Moser HW (1964) Abnormalities of serum gamma 1 A globulin and ataxia telangiectasia. Medicine 43: 423-433. 